\title{
The 2004 sequence of triggered earthquakes off the Kii peninsula, Japan
}

\author{
Sun-Cheon Park and Jim Mori \\ Disaster Prevention Research Institute, Kyoto University, Gokasho, Uji, 611-0011, Japan
}

(Received December 4, 2004; Revised March 18, 2005; Accepted April 5, 2005)

\begin{abstract}
We examine the spatial and temporal relationships of the sequence of strong earthquakes that occurred off the Kii Peninsula, Japan, on 5 September 2004. The first event (Mj 7.1) occurred at 10:07:08 (UTC) on a northward dipping plane within the subducting Philippine Sea plate. From 10:16 to 14:47 the seismicity shows a group of earthquakes ( $\mathrm{Mj} 3.2$ to 4.8$) 35 \mathrm{~km}$ to the east which are regarded as foreshocks to the second large earthquake. At 14:57:17, a Mw 6.1 strike-slip event occurred on a northwest trending plane. Some 14 seconds later, a large $(\mathrm{Mj} 7.4)$ thrust earthquake started $4.2 \mathrm{~km}$ southeast of the initial epicenter of the second earthquake. This largest earthquake is thought to have occurred on a southward dipping plane with the strike in an east-southeastly direction. Using the geometry of faults determined in this study, calculations of the Coulomb failure function show that simple static stress changes do not provide a good explanation for the triggering of the subsequent earthquakes.
\end{abstract}

Key words: Kii Peninsula, Nankai Trough, slip distribution, static stress, triggering, foreshocks.

\section{Introduction}

A strong series of events, including two large earthquakes with magnitudes greater than 7 , occurred on 5 September 2004 close to the Nankai Trough in southwest Japan. A Mj 7.1 earthquake (called the foreshock in this issue) started the sequence at 10:07:08 (UTC) and a Mj 7.4 earthquake (called the mainshock) occurred about $35 \mathrm{~km}$ to the east of the first earthquake about $5 \mathrm{hr}$ later. From the depths and locations, these two large thrust earthquakes are inferred to be intraplate events within the subducting Philippine Sea plate. The main purpose of this paper is to clarify the spatial and temporal characteristics of the two large earthquakes and the intervening seismicity.

The close spatial and temporal relationship between these earthquakes suggests that they did not occur by random chance, and that there was some triggering mechanism that connected the occurrence of these events. For a number of past earthquakes, static and dynamic stress changes have been proposed for triggering mechanisms of aftershocks and multiple events (e.g. Stein, 1999; Gomberg et al., 2003). Using the geometry determined for this sequence of earthquakes, we investigate the effect of Coulomb static stress changes (King et al., 1994) as a triggering mechanism.

Globally large thurst earthquakes at this location within a subduction zone are rather scarce (Christensen and Ruff, 1988). The locations and orientations of the fault planes determined in this study are probably one of the best recorded examples for these types of earthquakes and provide information about the regional stress field within the subducting Philippine Sea plate.

Copy right(C) The Society of Geomagnetism and Earth, Planetary and Space Sciences (SGEPSS); The Seismological Society of Japan; The Volcanological Society of Japan; The Geodetic Society of Japan; The Japanese Society for Planetary Sciences; TERRAPUB

\section{Sequence of Events}

We divide the sequence into four parts, as shown in Fig. 1. First is the Mj 7.1 earthquake (Event 1) that started the sequence at 10:07:08, second are the 'foreshocks' that occurred between 10:16 and 14:47 leading up to the second large earthquake (Event 2), third is the Mw 6.1 earthquake at 14:57:17 (Event 2A), and fourth is the $\mathrm{Mj} 7.4$ earthquake at 14:57:31 (Event 2B). We use regional and teleseismic waveform data to infer the geometry and size of the various earthquakes in this sequence. We will use the terms Events $1,2,2 \mathrm{~A}$, and $2 \mathrm{~B}$ to separate clearly the sequence of earthquakes.

\subsection{Event 1}

The Mj 7.1 earthquake at 10:07:08 (called the foreshock) occurred nearly under the Nankai Trough and determination of the moment tensor by the U. S. Geological Survey (USGS), Harvard University, National Research Institute for Earth Science and Disaster Prevention (NIED) agree that it was primarily a thrust earthquake, although the directions of strike and rake vary slightly between the solutions. To determine the orientation of the fault plane and the distribution of slip, we carried out a multiple-time window, finite-fault inversion (Hartzell and Heaton, 1983). Synthetic Green's functions for the inversion were calculated using a program of Langston and Helmberger (1975) with a onedimensional velocity structure modified from Nakanishi et al. (2002). The inversion procedure was carried out using a least-squares algorithm with a positivity constraint (Lawson and Hanson, 1974).

The data we used were teleseismic $P$ waves from 20 stations that represent a good azimuthal distribution around the earthquake. Recorded data were converted to displacement waveforms and high-pass filtered at $100 \mathrm{sec}$. The alignment of the data and model synthetics was done by visual inspection. The $P$ wave data for all the stations were quite 
Event 1: M7.1 Sep. 5 10:07:08
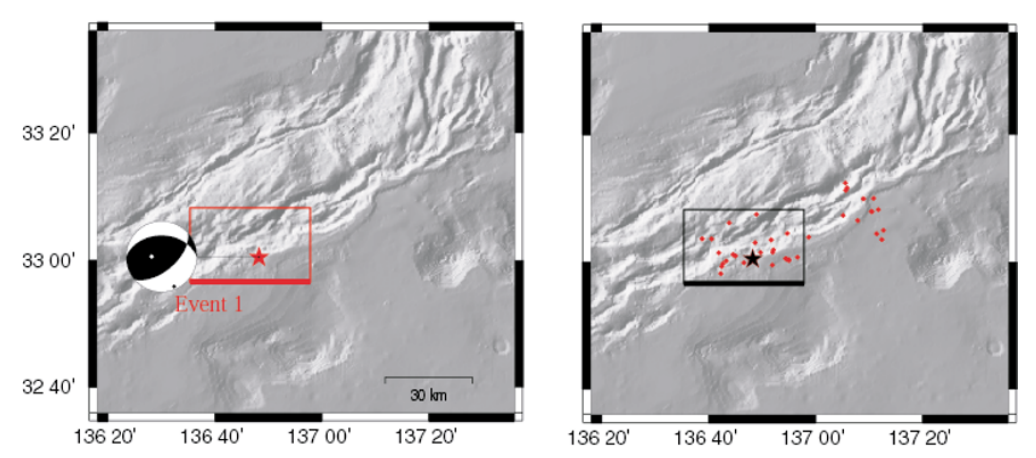

Event 2A: M6.1 14:57:17

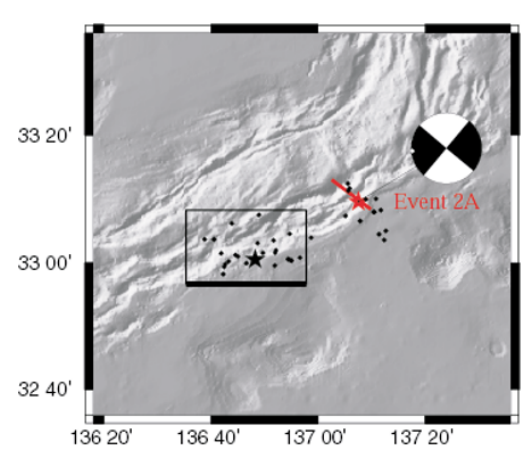

Event 2B: M7.4 14:57:31

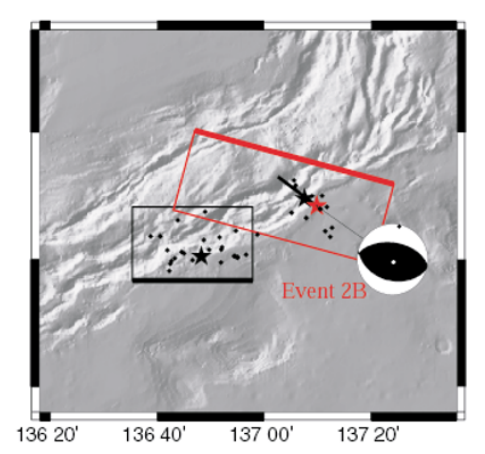

Fig. 1. Time sequence of earthquakes for the activity off the Kii Peninsula on 5 September 2004. Stars show epicenters of the larger earthquakes. Boxes show the approximate rupture areas of the two main events. Thicker lines of the boxes indicate the updip side for the dipping fault planes. The minimum magnitude of located earthquakes is about $\mathrm{Mj} 2.5$.

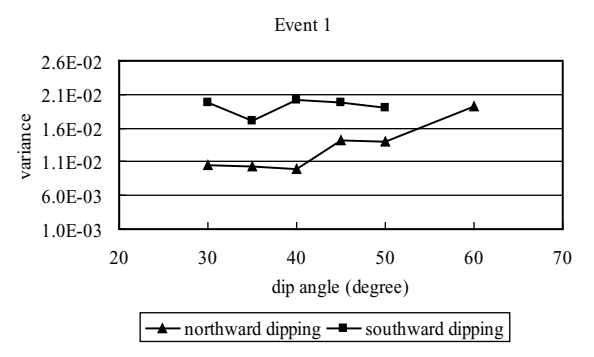

Fig. 2. Example of the variance as a function of dip for north and south dipping fault planes. The strike is fixed at $270^{\circ}$.

impulsive, so there was almost no ambiguity in picking the initial arrival. Data for the inversion and Green functions were sampled at $0.05 \mathrm{sec}$.

We divided the fault region into subfaults, 10 (along strike) by 5 (along dip), covering an area of $50 \times 47 \mathrm{~km}^{2}$. Preliminary runs of the inversion were carried to test the size of the fault area to find a reasonable size that contained the rupture area. Five time windows spaced at $2.5 \mathrm{sec}$ were used. The rupture process was parameterized by triangular source-time functions of $3 \mathrm{sec}$ duration. For the inversion runs we tested the north and south dipping fault planes for various orientations of the fault strike, dip angle, starting depth, and rupture velocity. As an example, Fig. 2 shows the model fits for various dips using a strike of $270^{\circ}$ and rupture velocity of $2.0 \mathrm{~km} / \mathrm{sec}$. For almost all of the cases that we tested, the north-dipping plane resulted in a better fit to the data. Our best-fitting final solution is for a strike of $270^{\circ}$, dip of $40^{\circ}$, starting depth of $20 \mathrm{~km}$ (Table 1), and rupture velocity of $2.0 \mathrm{~km} / \mathrm{sec}$. There was not a very strong constraint on the rupture velocity.

The final slip distribution in Fig. 3(a) shows a relatively simple pattern that has dimensions of about $40 \times 30 \mathrm{~km}^{2}$ with most of the slip in the region of the hypocenter. The estimated moment was $1.0 \times 10^{27} \mathrm{dyne} \cdot \mathrm{cm}$, which is equivalent to Mw 7.3. Similar to our results, Yagi et al. (2004) also reported a north-dipping fault. However, Yamanaka (2004) reported a south-dipping fault for this event. The depth and location of the earthquake show that it was an intraplate event within the subducting Philippine Sea plate.

\subsection{Foreshocks of Event 2}

Figure 1 shows the seismicity during the $4.5 \mathrm{hr}$ period from 10:16 to 14:47, following Event 1, using the relocations by Enescu et al. (2005) of the Japan Meteorological Agency (JMA) data. Aftershocks of Event 1 can be seen in the region of the fault plane. Also there is a group of earthquakes (12 events with magnitudes of $\mathrm{Mj} 3.2$ to $\mathrm{Mj}$ 4.8) which occurred about $35 \mathrm{~km}$ to the east of the Event 1 epicenter, in the area where Event 2 subsequently occurred. The earthquakes are outside the rupture area of Event 1 (Fig. 1) and appear to form a northwest-southeast trend which is similar to a feature seen in the aftershocks following Event 2. These events may be regarded as foreshocks to Event 2. Here we use the term 'foreshock', as in Jones (1984) where foreshocks are small events that are located close (within a few kilometers) to the mainshock, with the inference that 
Table 1. Source parameters determined for the earthquakes in this study.

\begin{tabular}{ccccccccc}
\hline Origin time (UTC) & Latitude & Longitude & Depth & Strike & Dip & Rake & Seismic moment & Mw \\
\hline Event 1 2004/09/05 10:07:08 & $33.0297^{\circ}$ & $136.8005^{\circ}$ & $20 \mathrm{~km}$ & $270^{\circ}$ & $40^{\circ}$ & $123^{\circ}$ & $1.0 \times 10^{27} \mathrm{dyne} \cdot \mathrm{cm}$ & 7.3 \\
Event 2A 2004/09/05 14:57:17 & $33.1597^{\circ}$ & $137.1250^{\circ}$ & - & $310^{\circ}$ & $90^{\circ}$ & $180^{\circ}$ & $2.0 \times 10^{25} \mathrm{dyne} \cdot \mathrm{cm}$ & 6.1 \\
Event 2B 2004/09/05 14:57:31 & $33.1403^{\circ}$ & $137.1637^{\circ}$ & $18 \mathrm{~km}$ & $105^{\circ}$ & $40^{\circ}$ & $94^{\circ}$ & $2.1 \times 10^{27} \mathrm{dyne} \cdot \mathrm{cm}$ & 7.5 \\
\hline
\end{tabular}

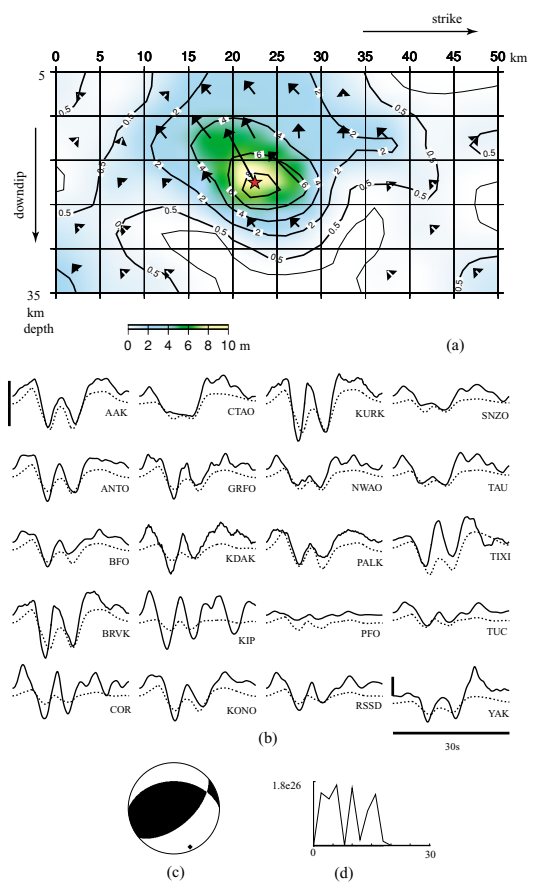

Fig. 3. Results of the teleseismic inversion of Event 1. (a) Slip distribution determined from the inversion. (b) Fit of model (dotted lines) to data (solid lines). Vertical scale bars indicate $0.01 \mathrm{~cm}$. Amplitudes of stations without a scale bar are on the same scale as AAK. (c) Average focal mechanism determined from the inversion. (d) Source time function.

they are occurring on the same fault as the mainshock. In this terminology, Event 1 is not considered to be a foreshock of Event 2.

We regard these earthquakes as foreshocks. However, they might be thought of as off-fault aftershocks of Event 1. They are intriguing because they seem to be a precursory activity to the larger earthquakes that subsequently occurred several hours later in the same location.

\subsection{Event 2A}

Event 2 (called the mainshock) initiated at 14:57:17 about $35 \mathrm{~km}$ northeast of the epicenter of Event 1 . The location is taken from Enescu et al. (2005). Using the $P$-wave first motions at 21 regional Hi-Net and F-Net stations (operated by NIED), we determined a strike-slip mechanism (strike $310^{\circ}$, dip $90^{\circ}$, rake $180^{\circ}$ ) on a vertical fault plane, as shown in Fig. 4. From the northwest trend of the foreshocks and aftershocks, the northwest striking nodal plane is inferred to be the fault plane. We label this initial earthquake Event 2A. From the following aftershock locations that form the northwest trending feature, the depth of faulting for this earthquake is inferred to be about 5 to $15 \mathrm{~km}$, which indicates that it probably occurred within the subducting Philippine Sea plate. We used regional $P$ waves

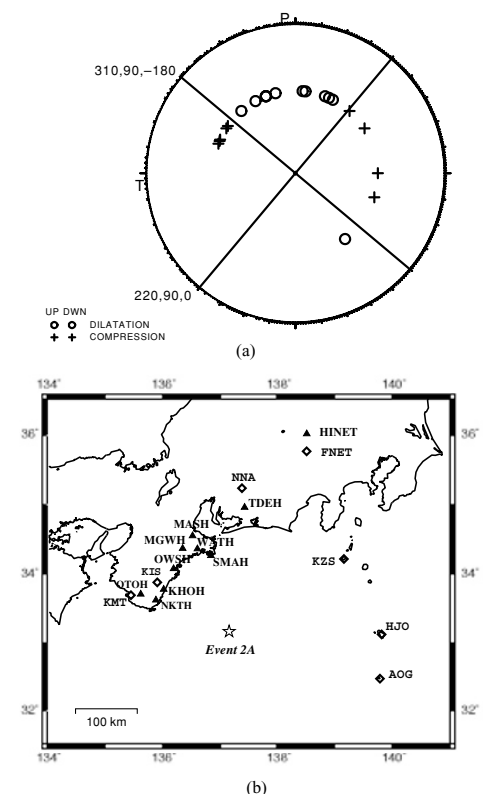

Fig. 4. (a) Focal mechanism determined from $P$ first motions (b) Stations used for focal mechanism determination.

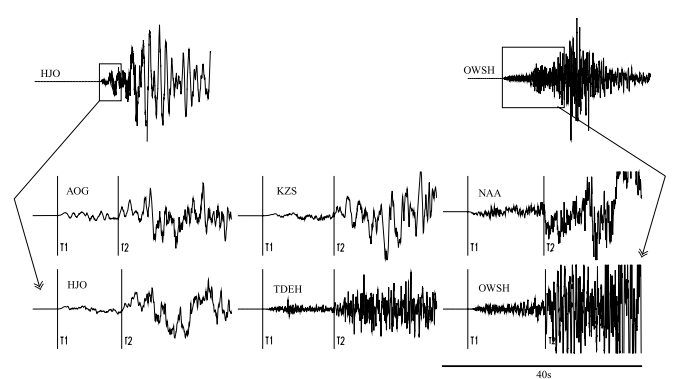

(a)

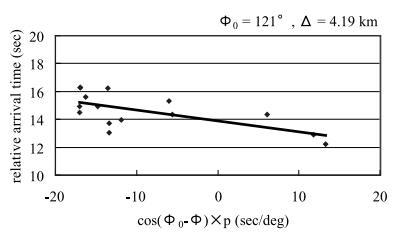

(b)

Fig. 5. (a) Examples of regional waveforms showing the large arrival of Event $2 \mathrm{~B}$ about $14 \mathrm{sec}$ after Event 2A. (b) $P$ arrival times of Event $2 \mathrm{~B}$ relative to Event $2 \mathrm{~A}$. The line is a least-squares fit for a location of Event $2 \mathrm{~B}, 4.2 \mathrm{~km}$ at an azimuth of $121^{\circ}$ from Event $2 \mathrm{~A}$.

on F-Net stations and estimated the seismic moment to be $2.0 \times 10^{25}$ dyne $\cdot \mathrm{cm}$ by comparing the recorded data to synthetic $P$ waveforms calculated for the strike-slip mechanism and a one-dimensional velocity structure. This moment is equivalent to Mw 6.1. 


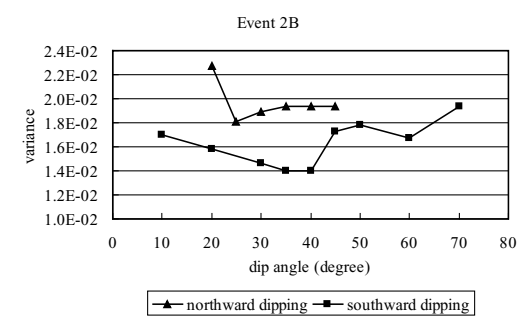

Fig. 6. Example of the variance as a function of dip for north and south dipping fault planes. The strike is fixed at $105^{\circ}$.
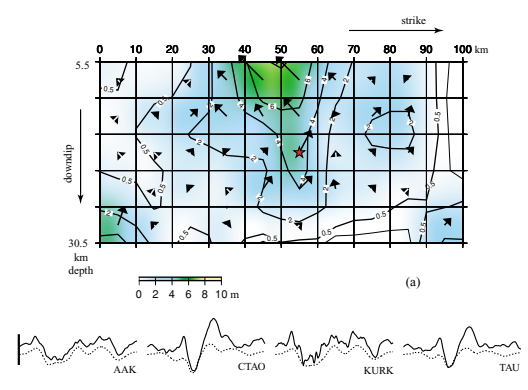$$
\text { YAN }
$$$$
\text { Awrar mañ }
$$

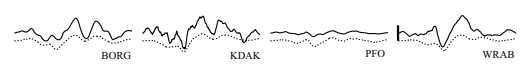$$
\text { Aw }
$$

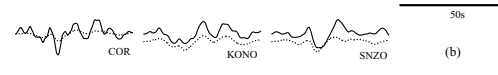

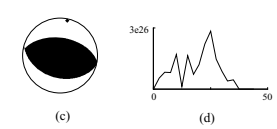

Fig. 7. Results of the teleseismic inversion of Event 2B (a) Slip distribution determined from the inversion (b) Fit of model (dotted lines) to data (solid lines) (see Fig. 3(b) for vertical scale). (c) Average focal mechanism determined from the inversion (d) Source time function.

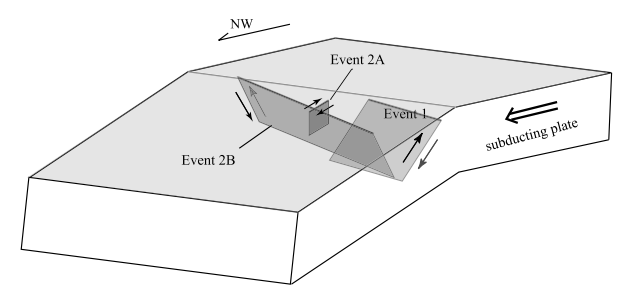

Fig. 8. Schematic diagram of the faulting geometry for the earthquakes of the 2004 sequence off the Kii peninsula.

\subsection{Event 2B}

About $14 \mathrm{sec}$ following the initiation of Event 2, large amplitude $P$ arrivals can be seen on both regional and teleseismic seismograms. Examples of some of the regional waveforms are shown in Fig. 5(a). Using the timing of these arrivals relative to the initial $P$ waves at 15 regional stations, we estimated that the initial source of the large amplitude waves was located $4.2 \mathrm{~km}$ to the southeast (azimuth $121^{\circ}$ ) of the initiation (Fig. 5(b)). This direction is very close to the strike of the inferred fault plane of Event $2 \mathrm{~A}$, and suggests that Event 2B initiated near the southeast edge of Event $2 \mathrm{~A}$.
Table 2. Results of $\triangle C F F$ calculations for various source and receiver faults. ' + ' indicates a $\triangle C F F$ value consistent with faulting. '-' indicates a $\triangle C F F$ value inconsistent with faulting. Mechanism (strike, dip, rake) : South-dipping Event 1 (90, 40, 77), North-dipping Event 1 (270, 40, 123), Event 2A (310, 90, 180), South-dipping Event 2B (1) (105, 40, 63), South-dipping Event 2B (2) (90, 40, 90), North-dipping Event 2B (1) (279, 50, 86), North-dipping Event 2B (2) (270, 40, 90). Horizontal row - Source fault, vertical row - receiver fault.

\begin{tabular}{cccc}
\hline & $\begin{array}{c}\text { South-dipping } \\
\text { Event 1 }\end{array}$ & $\begin{array}{c}\text { North-dipping } \\
\text { Event 1 }\end{array}$ & Event 2A \\
\hline Event 2A & - & - & \\
South-dipping Event 2B (1) & - & + & + \\
South-dipping Event 2B (2) & + & + & - \\
North-dipping Event 2B (1) & - & - & + \\
North-dipping Event 2B (2) & + & + & - \\
\hline
\end{tabular}

Teleseismic (USGS and Harvard moment tensors) and regional (NIED moment tensor) waveform analyses indicate that Event 2 was primarily a thrust event, so we infer that the thrust faulting initiated at this time, $14 \mathrm{sec}$ following the initial strike-slip event. This earthquake is labeled Event 2B.

Using the same methods described for Event 1, we carried out a teleseismic waveform inversion to determine the fault orientation and slip distribution for Event 2B. Data were teleseismic $P$ waves from 23 stations. The fault grid for the inversion was 10 (along strike) by 5 (along dip) covering an area of $100 \times 39 \mathrm{~km}^{2}$. Five time windows spaced at $2.5 \mathrm{sec}$ were used. The alignment of the data was again done by visual inspection and, compared to Event 1, there was more ambiguity, since we chose the start of the large arrivals about $14 \mathrm{sec}$ following Event $2 \mathrm{~A}$ for the data used in the inversion. The estimated uncertainty in the arrival was about $1.0 \mathrm{sec}$, which probably does not make a large difference to the results. The time for the rupture to travel between adjacent subfaults in the model is about $4 \mathrm{sec}$.

Similar to Event 1, we searched for the best-fitting fault geometry. There was a significant improvement of the fits for stations located toward the south using a fault that dipped toward the south, as compared to a fault that dipped toward the north. The fit of the waveforms also consistently showed a better fit for a range of strike directions (Fig. 6), which shows the fit for various dip angles using a strike of $105^{\circ}$. Our best fitting model is for a strike $105^{\circ}$, dip $40^{\circ}$, and rupture velocity of $2.0 \mathrm{~km} / \mathrm{sec}$ (Table 1). In general, the determination of the fault plane for Event $2 \mathrm{~B}$ was more robust than for Event 1.

The slip distribution in Fig. 7(a) shows that faulting occurred over a length of about $80 \mathrm{~km}$ with a moment of $2.1 \times$ $10^{27}$ dyne $\cdot \mathrm{cm}$, which is equivalent to $\mathrm{Mw}$ 7.5. The area of largest slip was in the shallow region updip of the hypocenter. Yagi et al. (2004) also determined that the southward dipping plane was likely the fault plane. However, results of other waveform modeling studies give different geometries for the fault plane of this earthquake (e.g. Wu et al., 2004; Yamanaka, 2004).

It is difficult to distinguish if there is a continuous rupture between Events $2 \mathrm{~A}$ and 2B, or if they should be regarded as distinct earthquakes separated in space and time. The spatial and temporal separations are not typical of normal 


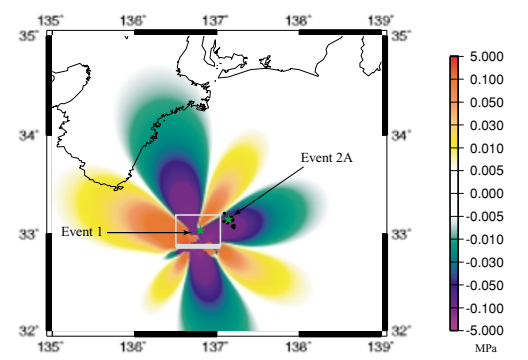

(a)

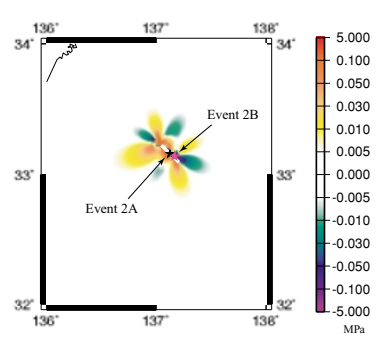

(b)

Fig. 9. (a) $\triangle C F F$ distribution from the slip distribution of Event 1 (fault area indicated by a rectangle) calculated for the strike-slip mechanism (strike $310^{\circ}$, dip $90^{\circ}$, rake $180^{\circ}$ ) of Event $2 \mathrm{~A}$. Calculation is for a depth of $10 \mathrm{~km}$. Black dots indicate the epicenters of the foreshocks of Event $2 \mathrm{~A}$. (b) $\triangle C F F$ distribution from Event $2 \mathrm{~A}$ (fault indicated by white solid line) calculated for the thrust mechanism (strike $105^{\circ}$, dip $40^{\circ}$, rake $63^{\circ}$ ) of Event 2B. Calculation is for a depth of $18 \mathrm{~km}$. The calculations were done using an apparent coefficient of friction of 0.4 .

rupture velocities ( $4 \mathrm{~km}$ over $14 \mathrm{sec})$, and the significantly different focal mechanisms suggest that they are separate earthquakes, so we interpret our results as indicating that they are separate events.

\subsection{Sequence summary}

The results of the data analyses described above can be summarized by the following description of the sequence of earthquakes. The activity started with a $\mathrm{Mj} 7.1$ earthquake (Event 1) within the subducting Philippine Sea plate under the Nankai Trough. The earthquake occurred on a north-dipping fault plane trending nearly east-west, with dimensions of about $40 \times 30 \mathrm{~km}^{2}$. Following Event 1 , regular aftershocks were seen in the rupture area, plus a small group of earthquakes ( $\mathrm{Mj} 3.2$ to $\mathrm{Mj} 4.8$ ) occurred $35 \mathrm{~km}$ to the east, close to the location of the subsequently occurring Event 2A. These earthquakes are considered to be foreshocks to Event 2A. About $5 \mathrm{hr}$ after Event 1, a Mw 6.1 strike-slip earthquake (Event 2A) occurred on a steeplydipping, northwest trending fault in the area of the foreshocks. Some 14 seconds after Event 2A, Event 2B, the largest earthquake of the sequence $(\mathrm{Mj} 7.4)$, occurred close to Event 2A. Event 2B was a thrust event that ruptured a south-dipping, east-southeast trending fault plane, with dimensions of about $80 \times 30 \mathrm{~km}^{2}$. All of these earthquakes are thought to have occurred within the subducting Philippine Sea plate. The combined geometry of all of the earthquakes is shown in Fig. 8. Other studies (e.g. Baba et al., 2005; Satake et al., 2005) suggest that the Mj 7.4 earthquake resulted from multiple faulting. This is consistent with our interpretations of Events $2 \mathrm{~A}$ and $2 \mathrm{~B}$, even though there is still some discrepancy in the suggested fault geometries.

\section{Static Stress Triggering}

The close spatial occurrence of Event 2A, along with its preceding foreshocks following Event 1, are suggestive of static stress triggering. Using the fault geometry determined in the previous section, we calculated the Coulomb failure function (e.g. King et al., 1994) to evaluate the effect of simple static stress triggering. We used the slip distribution of Event 1 on a northward dipping plane and calculated the static stress change $(\triangle C F F)$ for the strike-slip mechanism obtained for Event $2 \mathrm{~A}$ at a depth of $10 \mathrm{~km}$, using the fol- lowing expression.

$$
\Delta C F F=\Delta \tau+\mu^{\prime} \cdot \Delta \sigma_{n} .
$$

The changes in shear stress, $\Delta \tau$, and normal stress, $\Delta \sigma_{n}$, were calculated using the program of Okada (1992) and the value of the apparent coefficient of friction, $\mu^{\prime}$, was set to 0.4 . The $\triangle C F F$ contribution from the slip of each subfault was summed on a grid with spacing of $0.02^{\circ}$ to produce the distributions shown in Fig. 9.

We found that for the strike-slip mechanism of Event 2A, the region of the foreshocks and the initiation of Event $2 \mathrm{~A}$ is a strongly negative region (Fig. 9(a)). This indicates that the slip from Event 1 does not cause static stress changes conducive to the triggering of Event $2 \mathrm{~A}$ nor its foreshocks.

For the large thrust earthquake, Event $2 \mathrm{~B}$, the largest static stress changes was probably due to the closely located strike-slip Event 2A. At such close proximity, one needs a detailed slip distribution for Event $2 \mathrm{~A}$ to accurately evaluate the static stress changes in the region of the initiation of Event 2B, which is not available. However, if one assumes that Event $2 \mathrm{~B}$ initiated near the southeastern end of the fault (as indicated by the relative location), for simple slip distributions on the strike-slip fault, the initiation of a southward dipping thrust event is in a highly negative region (Fig. 9(b)). Static stress changes from a simple strike-slip fault are not conducive to the triggering of the reverse fault mechanism of Event 2B.

Using our preferred model, we showd that simple static triggering is not consistent with the occurrence of Events $2 \mathrm{~A}$ and $2 \mathrm{~B}$. However, we acknowledge that there are many variables and conditions that were assumed in the calculation. It is difficult to evaluate the whole range of variability for all of these parameters. However, we carried out some calculations for representative cases to check the results. First we repeated the calculations for a range of $\mu^{\prime}$ from 0.1 to 0.7 . Since Event $2 \mathrm{~A}$ is in a strongly negative part of the static stress distribution, the different values of $\mu^{\prime}$ did not significantly change the results, and Event $2 \mathrm{~A}$ is consistently in a negative region. The depth of Event $2 \mathrm{~A}$ is not well determined, so we also tested various depths from 5 to $15 \mathrm{~km}$. Since Event $2 \mathrm{~A}$ is a vertical strike-slip fault, the depth dependence is not strong and again Event $2 \mathrm{~A}$ consistently falls in a negative region. 
The largest differences in the effects of static triggering for this sequence probably arise from the differences in geometry of the source fault and triggered earthquake. For example, we determined a northward dip for Event 1, while other studies (e.g. Yamanaka, 2004) reported a southward dip. We calculated the $\triangle C F F$ for several different geometries of the source and receiver faults, with the results summarized in Table 2. A ' + ' in Table 2 indicates that the $\triangle C F F$ was conducive to faulting, and a ' - ' indicates $\triangle C F F$ inconsistent with the faulting. For the various source fault geometries, we used the best-fitting slip distributions from our teleseismic inversions. In Table 2 there are a variety of positive and negative triggering conditions. However, one significant result is that both a north and south dipping fault for Event 1 produce negative $\triangle C F F$ effects for the strike-slip mechanism of both Event $2 \mathrm{~A}$ and its foreshocks. The effect of Event $2 \mathrm{~A}$ on Event $2 \mathrm{~B}$ is difficult to judge because of the close proximity of the two events, where small changes in fault geometry and the unknown slip distribution have great effect on the $\triangle C F F$.

In all of these calculations, we assume that the static stress level at the hypocenter of the triggered event is the important value, instead of looking at the stress change over the whole fault plane. This is probably reasonable because, at these distances to a triggered fault, once a rupture begins, the dynamic stress changes associated with the rupture front are much larger than the static stress changes (e.g. Abercrombie and Rice, 2005).

Since the simple Coulomb failure function does not seem to provide a good explanation for the triggering of Events $2 \mathrm{~A}$ and $2 \mathrm{~B}$, further investigation of static and dynamic triggering mechanisms is needed to explain this sequence.

\section{Outer-Rise Earthquakes}

Large thrust earthquakes in the vicinity of the trench and outer-rise of subduction zones are not common events worldwide. Christensen and Ruff (1988) identified some regions that have outer-rise compression earthquakes, with subduction zones that are strongly coupled. The idea is that the compressive stress from the oceanward side accumulates if the slip is locked on the subduction interface. For more weakly coupled subduction zones, where slip is occurring on the subduction interface, the amount of accumulated compressive stress is less, and the bending stresses near the outer rise dominate, producing mainly normal faulting earthquakes. The recent thrust earthquakes in 2004 seem to be consistent with the idea of a strongly coupled subduction zone that produces compression earthquakes near the outer-rise.

\section{Conclusions}

We used teleseismic and regional data to determine the faulting geometries of the earthquakes of the sequence that occurred off the Kii Peninsula near the Nankai Trough on 5 September 2004. Our results show that the activity began with a Mw 7.3 thrust earthquake (Event 1) on a northdipping fault. Following this event, there was foreshock activity of M3-M4 earthquakes prior to a Mw 6.1 strikeslip earthquake (Event $2 \mathrm{~A}$ ) that occurred about $35 \mathrm{~km}$ to the east. Some $14 \mathrm{sec}$ after the initition of Event 2A, the largest earthquake (Event 2B) of the sequence occurred. This was a Mw 7.5 thrust event on a south-dipping fault plane that had a rupture length of about $80 \mathrm{~km}$.

Calculations of the Coulomb failure function for the fault geometries determined in this study, indicates that the triggering of Events $2 \mathrm{~A}$ and $2 \mathrm{~B}$ is not well explained by simple static stress changes.

Acknowledgments. We gratefully acknowledge the use of $\mathrm{Hi}-$ Net and F-Net waveform data from the National Research Institute for Earth Science and Disaster Prevention (NIED), and waveform data from the Incorporated Research Institute for Seismology (IRIS) data center. Bathymetry data in Fig. 1 was obtained from the webpage of the Japan Oceanographic Data Center. We used the General Mapping Tool (GMT) for making some of the figures. We thank the EPS reviewers and editor for their helpful comments.

\section{References}

Abercrombie, R. A. and J. Rice, Can observations of earthquake scaling constrain slip weakening? Geophys. J. Int., 2005 (in press).

Baba, T., P. R. Cummins, and T. Hori, Compound fault rupture during the 2004 off the Kii Peninsula earthquake (M 7.4) inferred from highly resolved coseismic sea-surface deformation, Earth Planets Space, 57, 167-172, 2005.

Christensen, D. and L. J. Ruff, Seismic coupling and outer rise earthquakes, J. Geophys. Res., 93, 13,421-13,444, 1988.

Enescu, B., J. Mori, and S. Ohmi, Double-difference relocations of the 2004 off the Kii peninsula earthquakes, Earth Planets Space, 57, this issue, 357-362, 2005.

Gomberg, J., P. Bodin, and P. A. Reasenberg, Observing earthquake triggering in the near field by dynamic deformations, Bull. Seism. Soc. Am., 93,118-138, 2003.

Hartzell, S. H. and T. H. Heaton, Inversion of strong ground motion and teleseismic waveform data for the fault rupture history of the 1979 Imperial Valley, California earthquake, Bull. Seism. Soc. Am., 73, 1553-1583, 1983.

Jones, L. M., Foreshocks (1966-1980) in the San Andreas system, California, Bull. Seism. Soc. Am., 74, 1361-1380, 1984.

King, G. C. P., R. S. Stein, and J. Lin, Static stress changes and the triggering of earthquakes, Bull. Seismol. Soc. Am., 84, 935-953, 1994.

Langston, C. A. and D. V. Helmberger, A procedure for modeling shallow dislocation sources, Geophys. J. R. astr. Soc., 42, 117-130, 1975.

Lawson, C. L. and R. J. Hanson, Solving Least-Squares Problems, 340 pp, Prentice-Hall, Inc., Englewood Cliffs, New Jersey, 1974.

Nakanishi, A., N. Takahashi, J-O. Park, S. Miura, S. Kodaira, Y. Kaneda, N. Hirata, T. Iwasaki, and M. Nakamura, Crustal structure across the coseismic rupture zone of the 1944 Tonankai earthquake, the central Nankai Trough seismogenic zone, J. Geophysic. Res., 107, B1, 10.1029/2001JB000424, 2002.

Okada, Y., Internal deformation due to shear and tensile faults in a halfspace, Bull. Seism. Soc. Am., 82, 1018-1040, 1992.

Satake, K., T. Baba, K. Hirata, S. Iwasaki, T. Kato, S. Koshimura, J. Takenaka, and Y. Terada, Tsunami source of the 2004 off the Kii Peninsula earthquakes inferred from offshore tsunami and coastal tide gauges, Earth Planets Space, 57, 173-178, 2005.

Stein, R. S., The role of stress transfer in earthquake occurrence, Nature, 402, 605-609, 1999.

$\mathrm{Wu}, \mathrm{C}$., K. Koketsu, and K. Hikima, Analysis of the source rupture process of the Southeast Off-shore Kii Peninsula earthquake from strong-motion records, 2004 Fall Meeting of the Seismological Society of Japan, 2004 (in Japanese).

Yagi, Y., T. Hara, and T. Kashima, Strong-motion records, CMT, and source process of the earthquake that occurred on September 5, 2004 southeast off-shore of the Kii Peninsula, 2004 Fall Meeting of the Seismological Society of Japan, 2004 (in Japanese).

Yamanaka, Y., Source process of the 2004 Southeast Off-shore Kii Peninsula earthquake, 2004 Fall Meeting of the Seismological Society of Japan, 2004 (in Japanese).

S.-C. Park (e-mail: suncheon@eqh.dpri.kyoto-u.ac.jp) and J. Mori 